\title{
Letter to the Editor: Serum Salivary and Pancreatic Amylase in Cystic Fibrosis
}

\author{
KEVIN F. MCGEENEY
}

Department of Medicine and Therapeutics, University College, Dublin, Ireland

It is regrettable that there is no method for the analytical determination of amylase which satisfies the criteria suggested by the International Union of Biochemistry (5). This lack is compounded by attempts to determine the pancreatic and salivary gland contribution to the total serum amylase. From recent letters $(2,9)$, it is apparent to one reader that there are gross methodologic barriers to be overcome. That amylase from the salivary gland and amlyase from the pancreatic gland may have different affinities for starch $(8)$ is not the main problem. The choice of method of separating the two enzyme activities from each other is the vital decision. Ideally, the method should be quick; it has been shown that amylase can undergo deamidation and deglycosidation (3). Amylase may be inactivated at low pH values (7). The differential temperature sensitivity of salivary and pancreatic amylase in serum has been suggested as an analytical aid (1). It is my opinion that the use of polysaccharides and/or sugars in separation or in the milieu of subsequent activity determination is to be avoided. So too are methods involving densitomitry and or planimitry. Although all the foregoing objections are not inherent in any one method, they do underscore the difficulties.

It was the recognition of these problems which led to the development of a new method for the differential determination of salivary type and pancreatic type amylase in serum (6). This method uses a protein isolated from wheat which inhibits the activity of salivary type amylase one hundred times more than it inhibits the pancreatic type. The use of this inhibitor method has the advantage that the assay of salivary and pancreatic type amylase is very quick (less than one hr), and multiple samples can be assayed at the same time without special equipment. It is possible that the fact that the inhibitor does not completely inhibit the salivary type amylase may be seen as a disadvantage. This apparent shortcoming can be overcome by proper standaridization, which is technically not very damanding. As yet, the method has not been used in many laboratories; perhaps if it is more widely adopted, more opinion will be voiced, and other difficulties will be uncovered.

The inhibitor method has been used in the analysis of serum amylase in cystic fibrosis (CF) (4). The distribution of total amylase was skewed in both control and groups. So too was the distribution of pancreatic and salivary type amylase in both groups. Because of this, the results were treated by nonparametric statistical methods, and the median rather than the mean was reported. Elevated salivary amylase was not found in those $C F$ patients with pancreatic insufficiency. It was noted that log transformation did normalize the distribution of pancreatic type enzyme in both the controls and CF. In the control group, the distribution of salivary type amylase was normalized by $\log$ transformation, whereas in the CF group this was not the case. This difference in distribution of salivary type amylase in CF may indicate a subpopulation. This deduction would require more detailed examination with greater number of patients.

The study of an enzyme which occurs in both the salivary and pancreatic glands, with proper care, ought to give not only an understanding of amylase dynamics in CF but information on the development of fibrosis of the pancreas in this disease.

\section{REFERENCES AND NOTES}

1. Donaldson, L. A., McIntosh. W. B., and Brodie, M. J.: Amylase thermolability in body fluids. Scand. J. Gastroenterol., 12: 637 (1977).

2. Forstner, G. G., and Davidson, G.: Letter to the editor: amylase isoenzymes in cystic fibrosis. Pediatr. Res.. 13: 1077 (1979).

3. Karn, R. C.. Shulkin, J. D., Merritt, A. D., and Newell, R. C.: Evidence for posttranscriptional modification of human salivary amylase $\left(\mathrm{Amy}_{1}\right)$ isozymes. Biochem. Genet., 10: 341 (1973).

4. Kenny, D., Cooke, A., Tempany, E., and McGeeney, K. F.: Activity of serum amylase in cystic fibrosis. Clin. Chim. Acta, 89: 129 (1978).

5. Marshall. J. J.: On the use of "defined substrates" for measurement of $\alpha$ amylase activity (Letter to the Editor). Clin. Chem., 25: 1675 (1979).

6. O'Donnell, M. D., FitzGerald, O., and McGeeney. K. F.: Differential serum amylase determination by use of an inhibitor and design of a routine procedure. Clin. Chem., 23: 560 (1977)

7. Stiefel, D. J., and Keller, P. J.: Preparation and some properties of human pancreatic amylase including a comparison with human parotid amylase. Biochim. Biophys. Acta, 302: 345 (1973).

8. Stiefel, D. J., and Keller, P. J.: Comparison of human pancreatic and parotid amylase activities on different substrates. Clin. Chem., 2l: 343 (1975).

9. Wolf, R. O., and Taussig, L.: Letter to the editor: serum salivary amylase in cystic fibrosis. Pediatr. Res., 13: 1076 (1979). 